\title{
INNOVATION CLUSTERS IN PETROCHEMICAL INDUSTRY IN
}

\author{
ASIA-PACIFIC ZONE \\ Trifonova Natalia Victorovna \\ Saint-Petersburg State University of Economics, Russian Federation \\ Klementovichus Yana Yazepovna \\ Saint-Petersburg State University of Economics, Russian Federation \\ Borovskaya Irina Leonidovna \\ Saint-Petersburg State University of Economics, Russian Federation \\ Proshkina Aleksandra Sergeevna \\ Saint-Petersburg State University of Economics, Russian Federation \\ Vardanyan Irina Samvelovna \\ Saint-Petersburg State University of Economics, Russian Federation
}

\begin{abstract}
The article examines the role of innovation clusters in petrochemical industry in Asia-Pacific Zone. According to Sapience Integra model, the key element of an innovation cluster is an intellectual result cluster functioning, including technologies, skills and competencies, as well as knowledge. The dynamics of the intelligence core of the innovation cluster is analyzed on the example of the petrochemical industry in various zones in Asia-Pacific Zone.
\end{abstract}

Keywords: innovation cluster, petrochemicals, Asia-Pacific Zone, sustainability

JEL code: L10, O31, 032

\section{Introduction}

In Asia-Pacific Zone there is a tendency for swift development in different industries. According to the World Bank, in 2015 the contribution of this region to a global growth was twice higher than other developing regions. So in the nearest future the role of Asia-Pacific Zone in the global economy is expected to expand.

Asia-Pacific Zone is a political and economic term concerning the countries located along the perimeter of the Pacific Ocean, including island states in the ocean itself. This territory provides $50 \%$ of the world population and $35 \%$ of the world GDP. It is formed by such countries as: 
- developed countries: Japan;

- major countries with a dynamically developing economy: China, India, Russia;

- $\quad$ asian tigers: South Korea, Singapore; Malaysia;

- $\quad$ asian dragons: Indonesia, Thailand, Vietnam.

Considering the economic growth rate in Asia-Pacific Zone (GDP growth of 5-7\% annually), the population growth and increasing of purchasing power in the region, such sectors as construction, production of construction materials, aircraft building, automotive industry, pharmacology, production of fertilizers are being vigorously promoted. These industries shape a demand for products of the oil and gas chemical industry. At present time the share of oil and gas chemistry in the GDP is significant. For example, in China the share is $30 \%$, in India the share is $12 \%$, in South Korea the share is $10 \%$. However, the endowment and the structure of the economy in each country shape a different picture for the industrial development.

A hallmark of the petrochemical development in Asia-Pacific is a creation of innovation clusters. The innovation cluster is defined by the authors as a fundamentally new type of territorial concentration and combination of the research potential, entrepreneurship and results of the interaction between the university and business community.

\section{Theoretical framework}

If in the 1980s the cluster was considered as an advanced type of industrial agglomerations, the territorial factor of the associations had been added to the focus of the study. At present time the researchers consider the clusters as innovative systems with the mechanisms of interaction for value generation.

Triple Helix concept shaped theoretical basis for development of the regional innovation policy. In comparison with other theories, this concept put a mark on the third cluster participant such as the educational structure or university. The approach to university-business partnership is totally different within the concept (Etzkowitz, H. \& Leydesdorff, L., 1995, p.14). Especially the participants go beyond the traditional cooperation. Knowledge transfer is a keystone for the successful interaction between university, business and state. Science represented by universities is considered as a main source for knowledge generation. The government sustained engagement by the developing or supporting the infrastructure for innovation clusters. It also responsible for establishing a legal framework for cluster functioning (Leydesdorff, L. \& Ivanova, I., 2014, p. 390).

Considering the types of organization within the cluster it is anticipated to highlight an intelligence core of innovation cluster. An intelligence core is assumed as a cumulative intellectual result of the innovation cluster functioning. The key elements of the intelligence core are technologies, skills, knowledge. The model of the dynamic intelligence core "Sapience Integra" (Fig. 1) implies the presence one of the elements within every innovation cluster. The dominance of the element means a dominant role by one of cluster's participants: university, business, state. 


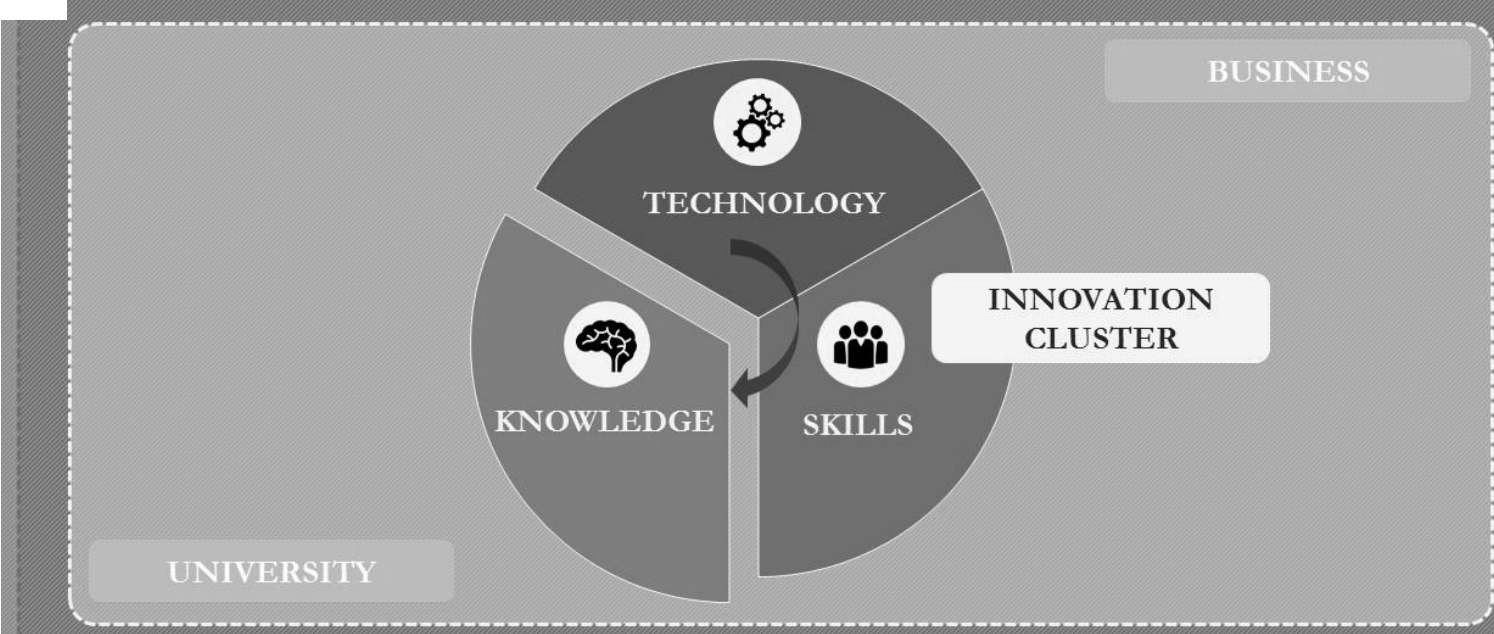

REGIONAL POLICY

Figure 1. "Sapience Integra" model of innovation cluster.

Authors: Trifonova N., Epstein M., Borovskaya I., Vardanyan I., Melnikova A., Proshkina A. (Saint-Petersburg State University of Economics)

The proposed model modifies the Triple Helix concept in the direction of specifying the nature and revealing the mobility factors of the sustainable component within the innovation cluster. At the same time, the main features of the Triple Helix concept approach are remained.

In the Sapience Integra model the dynamics in the intelligence core is determined by the influence of regional or national innovation policies. The process of knowledge generation is scrutinized in order to define the optimal way in cluster success. The example from petrochemical innovation clusters in the Asia-Pacific Zone give a clear view on the increasing role of innovation clusters in regional development.

\section{Results and Discussion}

\section{A Catalyst for Integration: technological development in petrochemicals.}

According to Mendeleev's opinion, "Oil burning (hydrocarbons) is practically the same as setting banknotes on fire. But even now the major volume of natural gas is used as petroleum. Natural gas has a $23-24 \%$ share in the world energy balance and its consumption is forecasted to increase $2-2,5$ times by 2050 due to its advantages in comparison with other hydrocarbons (various nature, origin, fractions, production and technologies). For example, the production of shale gas is expected to increase. Along with this growth, advanced gas processing and the use of gas as a raw material in petrochemical industry have illimitable opportunities. The area and the depth of hydrocarbon's processing is considered its most efficient and cost-effective advantages, when taking into account the growth of value added in the processing and increase the demand for products. Average price per metric ton of natural gas in the USA for 2015 was near 82 USD, ethane - 142 USD, ethylene - 400, low-density polyethylene (LDPE) 
- 1300. Meanwhile in Asia: ethylene - 1000 USD per metric ton, LDPE - 1160. Traditionally, the leading petrochemicals producing countries consume $8-10 \%$ of the total crude oil and more than $5 \%$ of the gas.

Gas-based petrochemicals have created a promising future for natural gas through technological breakthroughs, bridged diversities among gas chemicals nomenclature, and oil chemicals (from gas and oil feedstock). With these factors, a «golden gas age» is anticipated.

In this case, the gas-based petrochemicals industry is considered a developing and rapidly growing sector. In general, gas and oil can be processed through many different technological methods. A gas-based petrochemical is one of these methods. The petrochemical industry includes the part of chemical industry concerning oil and gas refining. Due to the historical features of the oil and gas industry in various countries (technological resource base, the general economic priorities, etc.), the focus can be either oil or gas - as a basic raw material. In countries with developed petrochemical industry, there exists a technological and resource infrastructure between the upstream and downstream sectors. For example oil and gas wells, oil refineries and gas processing plants, and petrochemical plants (especially in advanced gas extraction) have led to an increase in the volume and depth of the gas-based petrochemicals.

The strong interaction and the effective operation of numerous foreign industrial complexes and clusters, based on the raw materials and process diversity, justifies gas-based petrochemical's direction from a technological and an economical point of view. The growing importance of the natural and associated gas processing determines the crucial developing enterprises and/or integrated structures, business models with the use of gas and gas products as the basic raw materials as well as the usage appropriate technologies and innovations. Core processes and gas processing products make it possible to understand the complexity and specificity in gas-based petrochemicals. The natural gas composition is specific for each origin: in addition to the main component such as methane and water vapour, it includes ethane, propane, butane, incombustible gas - nitrogen, argon, carbon dioxide, also hydrogen sulfide, waxes, inert gases, and other impurities.

In preparation for processing, the gas is cleaned of most of the undesirable impurities. Also it is dried out. Some impurities may be used for further processing or sale. Through the Clauss process, the gas is purified from sulfur, which is used to create the important bi-product of sulfuric acid. During low-temperature gas condensation, a helium condensation product is obtained, then it is purified from impurities for helium. From the hydrocarbon, the following gas liquids (Natural Gas Liquids, NGL) are removed: ethane, propane, butane, isobutane, pentane; heavier hydrocarbons - gasoline or gas condensate (natural gasoil). After this the remaining pipeline quality dry natural gas is sent to the main gas pipes and can be used as fuel by residential, commercial and industrial consumers. Dry gas (primarily methane) can be liquefied (LNG) or compressed (CNG). Gas fuel is used for the production of motor fuel. Using gas to liquids (GTL) refinery, methane-rich gas could be converted into liquid synthetic fuels (gasoline, diesel fuel, fuel gas) either via direct conversion of methane to methanol or via processes of syngas generation and Fisher-Tropsch synthesis (or others). NGLs could be used for production of liquefied / liquid petroleum gas (LPG or LP gas), as propane or butane, or mixtures of both, used as fuel in heating appliances, cooking equipment, and vehicles. But 
the most profitable use of NGLs and methane is as a raw material for gas-based petrochemicals and chemistry: for the production of olefins, polyolefins, plastics, rubbers and other products (Figure 2).

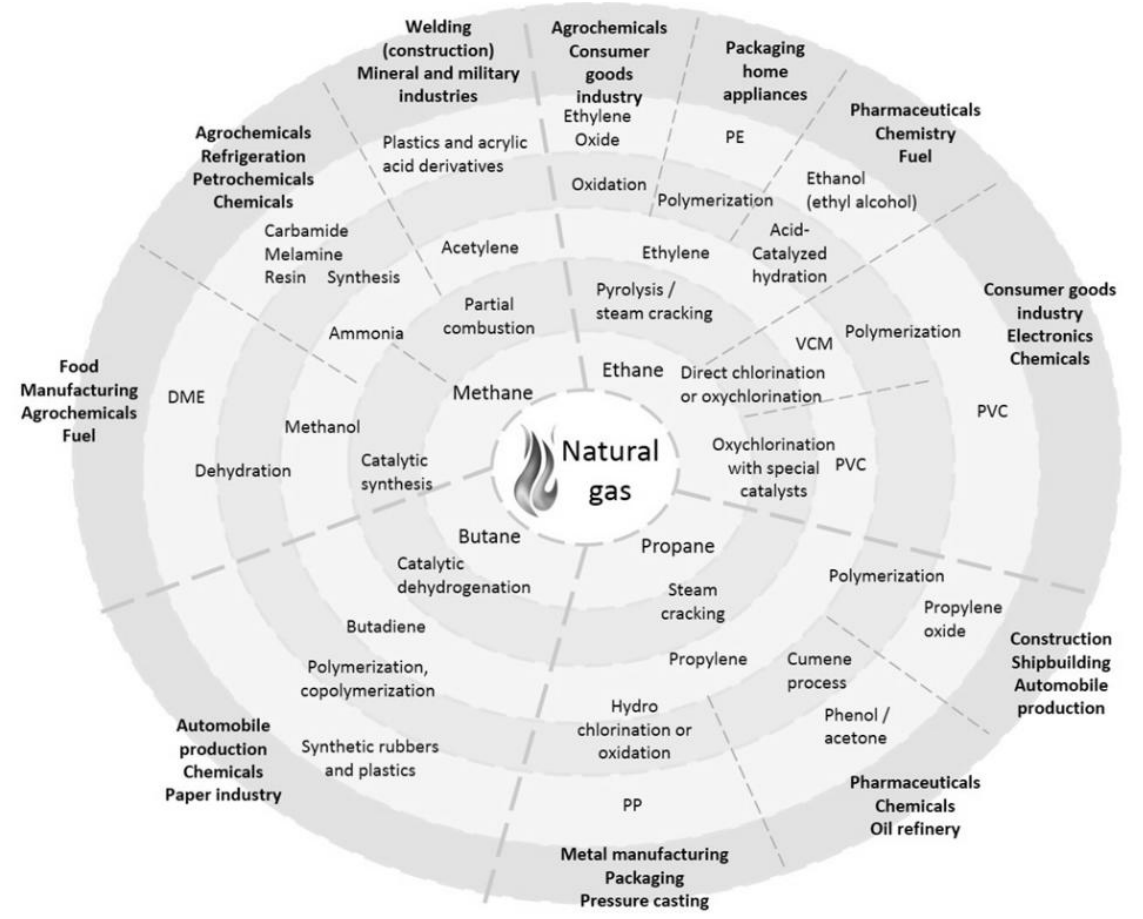

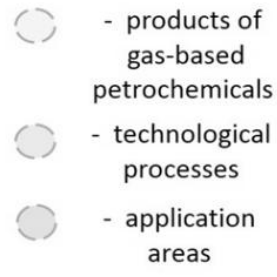

PE - polyethylene HDPE - high-density PE LDPE - low-density PE LLDPE - linear-low-density PE DME - dimethyl ether PP - polypropylene VCM - vinyl chloride monomer PVC - polyvinyl chloride MTBE - methyl tert-butyl ether ETBE - ethyl tert-butyl ether

Figure 2."Technological "bulb" on the developing petrochemical market.

Authors: Borovskaya I., Trifonova N. (Saint-Petersburg State University of Economics)

The main tendencies in gas-based petrochemicals are globalization, with country based petrochemical specialization; consolidation and integration; a changing regional structure, which is undergoing advanced development in the Asia-Pacific Zone. Considering these factors, there is a high demand for gas chemistry. These trends can explain the interest of the authors in considering the integration processes in the gas and chemical industry of the Asia-Pacific Zone.

The petrochemical industry is traditionally developed in a highly concentrated manner - oil and gas processing plants are located next to hydrocarbon sites and later petrochemical plants. In many countries, this concentration has different names: clusters, hubs, complexes. It can be a significant part of industrial cities, parks, and economic zones. Most processing plants are accompanied by suppliers, R\&D companies, and universities. Today the integration processes in the Asia-Pacific Zone are based on the availability of the raw resources, the demand from chemical industries, the production capacities and infrastructure.

\section{Innovation Petrochemical Clusters in Asia-Pacific Zone}

\section{Developed countries: Japan}

One of the world's economic centers, specializes in modern mechanical engineering, power 
engineering, metallurgy and chemical industry is Japan. The leading branch of international specialization is mechanical engineering, especially electronics, robotics and automotive. Mechanical engineering accounts for over $50 \%$ of the country's total exports. Japan can be classified as the "old" petrochemical center: it has all necessary infrastructure, qualified staff. Finally, the largest petrochemical companies and serious investors are already interested in the merchandise.

Japan covers a number of basic industries and continues to implement a niche strategy (petrochemical products with high added value), to counter intense competition from the Middle East. About one-third of China's ethylene consumption is covered by Japanese manufacturers. In addition, Chinese consumers are buying significant quantities of petrochemical products from Japan, as well, and other clients from the region of Southeast Asia.

In Japan, demand for gas is met by imports, domestic production of natural gas is about $3 \%$ of the total domestic demand for natural gas. Japan is the sixth in the world market by the total volume of natural gas consumption. Japan is the largest liquefied natural gas consumers. Among the Japanese petrochemical clusters the most significant is Mizushima Industry Complex. The largest members of the cluster are Asahi Kasei and Mitsubishi Chemical, which was one of the first to succeed in synthesizing methanol and ammonia from natural gas. Today the range of products manufactured by enterprises of the cluster is quite wide: formalin, trimethylolpropane, neopentylglycol, xylene, phthalic anhydride. Another major Japanese cluster is a complex in the Keiyō Industrial Zone. Its members include Idemitsu Kosan, Tonen general, Sumitomo Chemical. The main products of these plants are ethylene, propylene, acetaldehyde, benzene, toluene, xylene, styrene monomer, propylene oxide, isobutylene, n-butylene, LDPE, PP, ethylene-vinyl acetate copolymer resins, thermoplastic elastomers, polymer alloys, styrene butadiene rubber, ethylene propylene rubber, resorcinol.

\section{Developing countries:}

\section{China}

Chinese economy is in a stage of sustainable development. Moreover, it is transforming to become the largest economy in the world in next decade. The growth in the production of mineral fertilizers, automotive, mechanical engineering, food industry and others established world leadership of China in the production of petrochemicals. Over the past ten years China has increased the production of pyrolysis at two times. By the 2025 China is forecasted to double the consumption of methanol up to $25 \mathrm{mln}$ tons per year. Basically, this growth will be associated with the rapidly evolving MTO technology («methanol to olefins»). In addition, natural gas is widely used as a raw material in the production of fertilizers. At the same time, in spite of the unprecedented growth in capacity on a number of basic petrochemical products, China is a major importer oil and gas chemical products.

Despite the fact that China has its own gas reserves (6.2 trln cubic meters of reserves), due to 
the growing need in intensified imports of natural gas, $46 \%$ is imported through LNG. In 2014, China signed a contract for 30 years, which provides China with 38 bln cubic meters of Russian gas per year. «Power of Siberia» becomes a joint gas transmission system.

Among the largest innovation parks there is Shanghai Chemical Industrial Park (SCIP), which attracted a large number of petrochemicals leaders, such as BASF, Bayer, BP, Liquid Air, Royal Vopak, ChemChina and Sinopec. Also Dayawan Petrochemical Industrial is rapidly increasing its capacity. The general project within this park is a complex of oil refining from CNOOC and a joint venture between CNOOC-Shell - Nanhai Petrochemical Complex. By 2017 it is planned to increase oil refining up to 22 million tons per year and ethylene production - up to 2.2 million tons, by 2020 it is planned to enter the top 10 world largest petrochemicals clusters. 48 petrochemical enterprises in this park have been founded by international chemical and industrial giants (including Clariant, Bridgestone and BASF) from more than 20 countries. With a total investment of more than 130 billion yuan, these projects have a significant impact on the oil refining, production of ethylene, propylene and butylene in the region.

\section{India}

Indian economy is one of the largest in the world in terms of GDP. There was developed large-scale production of basic intermediates and petrochemicals so that petrochemical industry is a key sector of the economy. Internal demand pushed the growth with the main drivers in a wide range of packaging materials (annual consumption growth $-15 \%$ ), automobile production, construction, pharmaceuticals, synthetic fiber production (this fact provides the country a leading position in textile production). The demand on polymers, polyolefins, and rubber is supposed to grow on $7 \%$ in the near future. However, despite the fact that India is on the 8th place in the world for the production of petrochemical products, the country still has one of the lowest rate of petrochemical's consumption per capita in the world. For example, the polyester rate per capita - approximately $1.4 \mathrm{~kg}(6.6 \mathrm{~kg}$ China compared to $3.3 \mathrm{~kg}$ in the world).

India completes the demand for oil and gas only on $30 \%$ by its own so the country is forced import the feedstock, mainly from the Middle East countries. $14 \%$ of the total gas consumption is spent on chemicals. India is the fourth-largest consumer of LNG after Japan, South Korea and China (about $6 \%$ of the world market).

The government and the major industry representatives cooperate in the field of creating specialized industrial complexes - Petroleum, Chemicals \& Petrochemicals Investment Regions (PCPIRs). One of them is Dahej Petroleum, Chemicals \& Petrochemicals Investment Region, located in Gujarat, western India. The complex has an area of $453 \mathrm{~km} 2$, while the investment has exceeded $\$ 20$ billion. The scale of the project is determined by the discovery of oil and natural gas in Gandhar. The availability of raw materials and access to the sea port have provided favorable conditions for the petrochemicals in the region. The production chain in Dahej PCPIR includes gas cracking, ethyleneglycol, HDPE and PVC plants. In 2014 BASF 
has launched the production of polyurethane in this complex. The largest state-owned company - OGNC installed capacity for ethylene production to 1.1 million tons in Dahej PCPIR with the aim to meet the growing demand for polymers in India.

\section{Asian tigers:}

\section{Singapore}

The highly-diversified economy of Singapore provided the country to become an international center for many industries. The petrochemical industry of Singapore is one of the most developed in the world (11th place of petrochemical products production in the world).

Singapore showed a growth of petrochemical capacity in 2.5 - 4 times during the last 15 years (polyethylene - up to 2.4 million tons, polypropylene - up to 1.6 million tons.). Singapore's chemical industry is actively stimulated by the wide range of production in petroleum products from the basic polymers to complex products. This industry gives more than $30 \%$ of the total industrial production. A high demand for petrochemical products provides an internal inquiry from pharmaceutical, high-tech industries, and exports to neighboring countries as China and Vietnam.

Currently the major part of gas supply passes through a pipeline from Malaysia and Indonesia since Singapore has its own hydrocarbon resources. Singapore has ambitious plans to transform country into a leading LNG trading hub in Asia due to its strategic geographic location (Rogers H.V., 2016, p.42).

Singapore is one of the world's largest oil refining centers: Shell, ExxonMobil, Singapore Petroleum Company (SPC) and Singapore Refinery Company (SRC) are producing more than 1 million barrels per day. The idea of an integrated petrochemical complex to reduce transport costs and to use NGL or LPG as a feedstock is attractive to investors. In 1995, seven islands have merged into Jurong Island. Now the cluster brings together such companies as LANXESS, Afton Chemical, BASF, BP, Celanese, Evonik, ExxonMobil, DuPont, Mitsui Chemicals, Chevron Oronite, Shell, Singapore Petroleum Company and Sumitomo Chemical. The companies produce a wide range of products in several repartitions like ethylene, propylene, methane, polyolefin, plastics, etc.

\section{South Korea}

In South Korea the demand for petrochemical products is stimulated by the growing export-oriented industries (such as electronics, appliances, automotive). Almost half of the Korean chemical industry is presented by basic petrochemical products, including ethylene, $\mathrm{PE}$ and propylene. The production of these products in South Korea is the 4th largest in the world (after China, the US and Saudi Arabia).

It is noteworthy that Korea, producing $8.5 \mathrm{mln}$ tons per year of ethylene, which is used to 
produce synthetic rubbers, and other products (synthetic resins for plastic products, synthetic fiber raw materials for textiles, synthetic rubber, and other chemical-based products such as paints, detergents and adhesives), still exports $40 \%$ of these products. Because of the fierce competition in the region, South Korea stopped some chemical production (of ammonia, urea, methanol, etc.), and began to specialize in basic grades of polymers, of which China is an importer in the long term (PE, propylene, ABS plastics, etc.). Due to low production, almost all the demand for natural gas in Korea is satisfied by imports. Gas processing sector consumes $48 \%$ of the total volume, and industry $-20 \%$.

One of the largest petrochemical complexes is Yeosu petrochemical complex $(4,06 \mathrm{mln}$ tons of ethylene per year). It is set by the largest companies owned by Korean chaebols (LG, Samsung) and international companies, including Chevron and BASF, Kumho Petrochemical, Hanwha Chemical, and others.

Daesan petrochemical complex, which produces 3,11 mln tons of ethylene per year, consists of Hanwha Chemical, Total, LG Chemical and others. Finally, Ulsan petrochemical complex (1,33 mln tons of ethylene per year), is represented by Hanwha Chemical, Kumho Petrochemical, Lotte, BP Chemicals, SK Energy, BASF Korea and others.

\section{Malaysia}

Malaysia is one of the most developed economies in Southeast Asia. The leading industries of this country are construction, electronics, oil refining and chemicals. Petrochemicals are one of the leading industries, which produce a wide range of products from different stages of the oil-refining process: polyolefin, rubber, ethylene glycol, ethylene oxide and polystyrene, ethylbenzene and others. The development of the industry is both due to domestic demand (making tubes, flexible packaging, plastic bags and polyethylene films, electronics, rubber boots), and to exports (high demand on the processing of products from China, Cambodia, Vietnam). For example, more than $50 \%$ of the produced plastic is exported, and exports of rubber products exceed $\$ 11$ bln (about 5\% of total export). However, demand for the import of certain products is high: about 300 thousand tons of polyethylene is imported annually, as Malaysia is the largest producer and exporter of polyethylene stretch film (EIA, 2014).

Malaysia has the advantage of resource security (the country holds the 14th place in the world reserves of natural gas), the presence of the most developed in the Asia-Pacific gas pipeline network ( 1530 miles long), and the processing industry with its products. Malaysia is the world's second largest supplier of LNG.

In Malaysia, there are created large areas for the petrochemical production. In two of them natural gas is produced on the coast of Terengganu, is the main raw material. Each zone is an integrated complex with crackers and syngas facilities to produce basic feedstocks for downstream products.

In Kertih (Terengganu) Petronas Petrochemical Integrated Complex (PPIC) is located. It 
unites the processes from gas production and processing (based on 6 gas processing plants with a combined capacity of 2 million cubic feet (mmscf) of methaneper day in 2012) to production gas chemical products. The cluster has attracted partners such as BP Chemicals, The Dow Chemical Company, Sasol, Amoco. The main products of the cluster are as following: ethylene, ethylene oxide, butanol, praxylene, benzene, ammonia, PE, LDPE, polyvinyl chloride and others.

Gebeng (Pahang) is a major gas chemical hub for such international players as BASF, Reliance, Kaneka, Eastman and Polyplastics. Cluster products are acrylic acid and esters, syngas, butyl acrylate, butanediol, polyester copolymers, PP, polyacetals, etc.

\section{Asian dragons:}

\section{Indonesia}

Extraction and processing of oil and gas (mainly for export) in Sumatra, Java, Kalimantan, and in the western Irian Jaya play a significant role in economy of Indonesia. The main industrial centers are Jakarta, Surabaya, Yogyakarta, Palembang (oil and gas processing, metallurgy, mechanical engineering, chemicals, etc.). Economic growth also determines petrochemicals as one of the most profitable. The largest plastics' consumers in Indonesia are packaging industry and building materials. These industries consume more than half of the polymerics. Demand for petrochemicals is much higher than domestic supply. Indonesia took tenth place in the world in terms of gas reserves and is the largest owner of the stocks in the region, more than 70 percent of the country's natural gas reserves are located in the sea. The petrochemical sector consumes $11 \%$ of natural gas. Historically, the Indonesian production of natural gas was directed for export. Indonesia exports gas to Japan, South Korea and Taiwan. The Government of Indonesia has developed a program to establish 5 petrochemical industry clusters: Bali, Tuban, Balongan, Tangguh and Bontang. Among them is the Bontang complex in eastern Kalimantan. In this area, the state company PT Pupuk Kalimantan Timur is building a plant that can be called the largest for the production of ammonia and urea in the Asia-Pacific region. The installed capacity of the plant is 850,000 ton of ammonia and 1.15 million ton of urea per year. In addition, most of the natural gas is delivered to one of the largest LNG plants in the world - PT Badak NGL's plant in Bontang, where the LNG and LPG are manufactured.

\section{Conclusion}

The role of innovation clusters is increasing. Petrochemical industry in Asia-Pacific Zone as one of the most dynamically developed industries has shown a significant growth due to the activity of innovation clusters. Looking into the cluster's structure it is anticipated a synergy effect of interaction between government, business and educational structure. The more developed the cluster it is, the more influence it can have on regional cluster and innovation policies. There are a lot of studies on the impact of regional cluster policy on the activity of clusters. Also there are studies devoted to the influence of clusters on the economic 
development of regions. But there is a lack of studies on the specifics of regional and national policies. Taking into account the potential of research and business clusters as well as its defining role as a global center of knowledge, the research in this direction seems relevant and promising for the Asia-Pacific Zone.

\section{Acknowledgment}

The authors would like to offer our special thanks to our colleagues Melnikova A. and Epstein M. for their support and assistance with this project.

\section{Note}

This work was supported by St. Petersburg State University of Economics (St. Petersburg State University of Economics Academic Council Statement No. 12 on October 28, 2016).

This project was implemented under the Case Contest within Youth Day 2016: Dialogue of Generation, St. Petersburg Gas Forum. 


\section{References}

Al-Khazali O. M., Pyun C. S., \& Kim D. (2012) Are exchange rate movements predictable in Asia-Pacific markets? Evidence of random walk and martingale difference processes. International Review of Economics and Finance, 21, 221-231.

EIA (2014): EIA, International Energy Data and Analysis, Malaysia, available on-line http://www.eia.gov/beta/international/analysis.cfm?iso=MYS $(05.05 .2016)$.

Etzkowitz, H., \& Leydesdorff, L. (1995) The Triple Helix-University-Industry-Government Relations: A Laboratory for Knowledge-Based Economic Development. EASST Review 14, 14-19.

Hart, D. (2001) Innovation clusters: key concepts. The University of Reading, United Kingdom.

Leydesdorff, L., Ivanova, I. (2014) Mutual Redundancies in Interhuman Communication Systems: Steps Towards a Calculus of Processing Meaning. Journal of the Association for Information Science and Technology, 65, 2, 386-399.

Melnikova, A., Trifonova, N. \& Vardanyan, I. (2017) The innovative aspect of collaboration between universities and industry. Innovation, No. 3, p.47-50.

Park, S. C. (2007) Strategy for Innovative Clusters in Changwon Industrial Complex. South Korea, Korea Observer, Vol. 38, No.4,p. 523-554.

Perroux, F. (1950) The Domination Effect and Modern Economic Theory. Social Research, 17(2): 188-206.

Pongsaparn, R., Unteroberdoerster, O. (2011) Financial Integration and Rebalancing in Asia. Working Paper 11/243, International Monetary Fund, Washington.

Rogers, H. V. (2016) Asian LNG Demand: Key Drivers and Outlook. The Oxford Institute for Energy Studies.

Shah, N., Li, Z, Ierapetritou, M. (2011) Petroleum refining operations: Key issues, advances, and opportunities. Ind Eng Chem Res; 50(3):1161-70.

Shi, X. (2016) Gas and LNG trading hubs, hub indexation and destination flexibility in East Asia. Energy Policy.

Shinn, T. (2002) The Triple Helix and New Production of Knowledge: Prepackaged Thinking on Science and Technology. Social Studies of Science, 32(4), 599-614. 
Wang, J., Shapira, P. (2012) Partnering with Universities: A Good Choice for Nanotechnology Start-up Firms. Small Business Economics Vol. 38 Iss. 2.

Yuzhuo, C., Cui, L. (2015) The roles of universities in fostering knowledge-intensive clusters in Chinese regional innovation systems. Science Public Policy; 42 (1): 15-29.

Zhou, D. (2017) The Research on the Functions of Universities in an Innovation Cluster and the Realization Mechanisms. Open Journal of Business and Management, 5, 63-72.

Zhou, Z. (2013) Cluster development of natural gas utilization: theories and practices. Beijing: Science Press; 2013. 